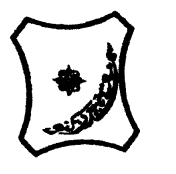

Bayero Journal of Pure and Applied Sciences, 10(1): 654 - 657

ISSN $2006-6996$

\title{
LEVELS OF SOME TRACE METALS AND THEIR POTENTIAL HEALTH RISKS IN WATER FROM KWADON BOREHOLES, GOMBE STATE, NIGERIA
}

\author{
Maigari, A. U*1, Umar Maryam M. ${ }^{2}$ and Sambo, M. S. ${ }^{3}$ \\ 1. Department of Chemistry, Gombe State University, Gombe \\ 2. Department of Integrated Science, FCE(T), Gombe \\ 3. Department of Chemistry, FCE(T), Gombe \\ ${ }^{*}$ Corresponding author: aishamaigari@yahoo.com
}

\section{ABSTRACT}

This study determined the levels of some metals in water from Kwadon boreholes which is a major source of drinking water to Gombe town and environs. The concentrations of these metals were then used to determine the chronic daily intake, the hazard quotient and the total hazard index on both adults and children to estimate the potential risk of the heavy metals determined. The results showed that manganese, copper and cobalt pose a potential health risk as their hazard quotients are greater than one with manganese having a CDI of $0.051 \mathrm{mg} / \mathrm{kg} /$ day for adults and $0.069 \mathrm{mg} / \mathrm{kg} /$ day for children which are above the recommended reference dose of manganese which is $0.04 \mathrm{mg} / \mathrm{kg} /$ day. The CDI for cobalt was found to be $0.001 \mathrm{mg} / \mathrm{kg} /$ day for both adults and children. This is higher than the recommended reference dose of cobalt which is $0.0003 \mathrm{mg} / \mathrm{kg} /$ day. Copper has a recommended reference dose of $0.004 \mathrm{mg} / \mathrm{kg} /$ day but the results for this study show a CDI value of 0.074 and $0.01 \mathrm{mg} / \mathrm{kg} /$ day for adults and children respectively. This is higher than the RfD and thus copper is a potential health risk. The Hazard Quotient (HQ) also shows that these three metals all have values higher than unity and they contribute to the Total Hazard Index (THI) giving it a high value of 13.225 for adults and $17.18 \mathrm{mg} / \mathrm{kg} /$ day for children.It is recommended that there is need for further monitoring of these metals in the water from Kwadon boreholes. Keywords: Chronic Daily Intake, Hazard Quotient, Health risk, Total Hazard Index.

\section{INTRODUCTION}

Water is a fundamental human need. It is an essential component of life, two thirds of the earth's surface is covered by water and the human body consists of $75 \%$ water, it is evidently clear that water is one of the prime elements responsible for life on earth. Fresh water constitute about $3 \%$ of the total water on the earth surface, only $0.01 \%$ of this fresh water is available (Hinrichsen and Tacio, 2002) but even this small portion of fresh water is under pressure due to anthropogenic sources caused by rapid growth in population and industrial activities (Li et al., 2009). Heavy metals are the main pollutants and elements of risk in drinking water (Enaam, 2013). Investigation of heavy metal contamination has been reported by researchers as an issue for concern.Researchers such as Koki et al., (2015), Maigari et al., (2016), Adamu et al., (2015), Nwachukwu et al., (2014) have all reported the levels of some metals and their potential health risks. Koki et al., (2015) have reported the effects of many metals on human health via different exposure routes. The objectives of this research to determine the levels of some heavy metals in water and to assess the health risks posed by the metals

\section{MATERIALS AND METHODS}

Water samples for analysis were obtained from various boreholes in Kwadon town directly from the source where tankers access the water for onward delivery to Gombe town and surroundings. The samples were taken early in the morning. All the samples were collected in polythene bottles which were washed with nitric acid and then severally with the water to be sampled. The water samples were preserved by acidifying to $\mathrm{pH}<2$ with $0.5 \mathrm{ml}$ concentrated $\mathrm{HNO}_{3}$ for trace metals analysis. Metal analysis was done using atomic absorption spectrometer. 


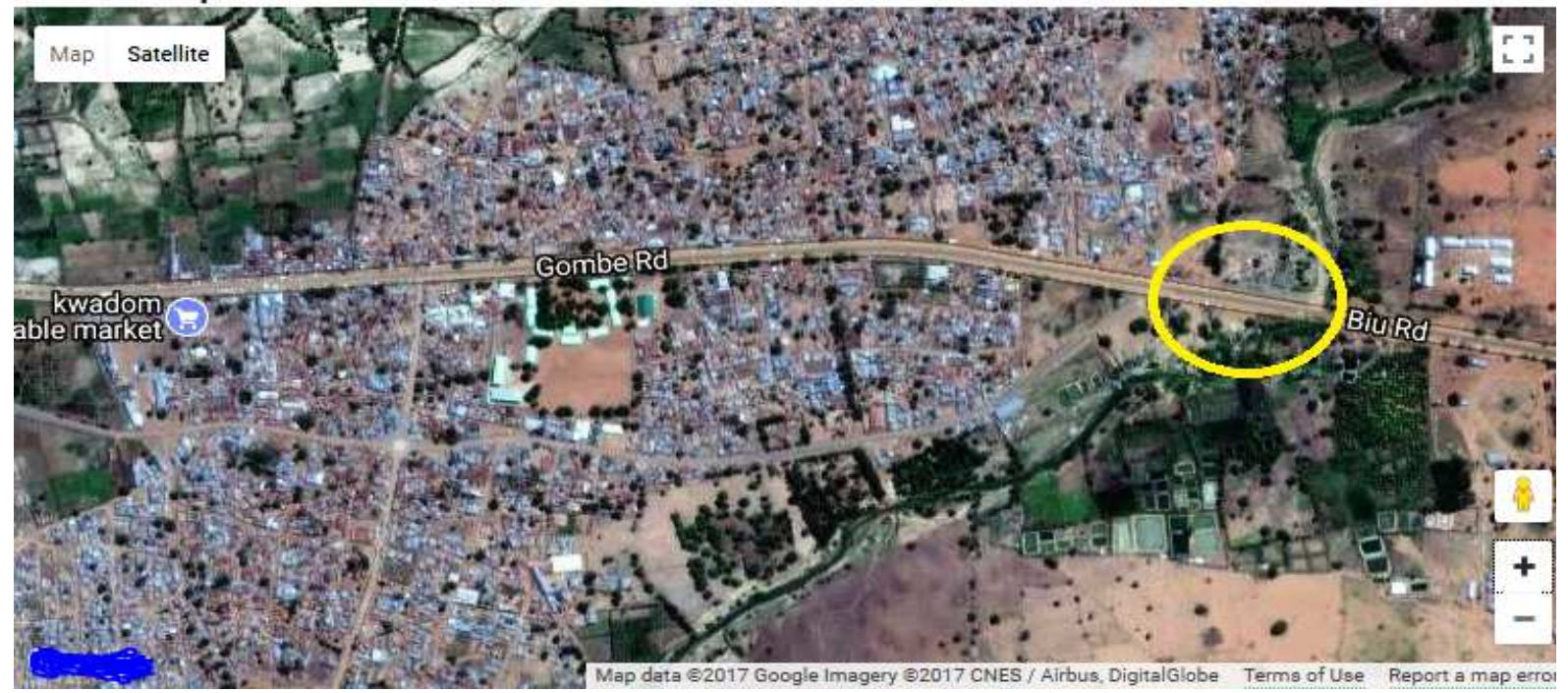

Arial Map of Kwadon Town, Gombe State, Nigeria.

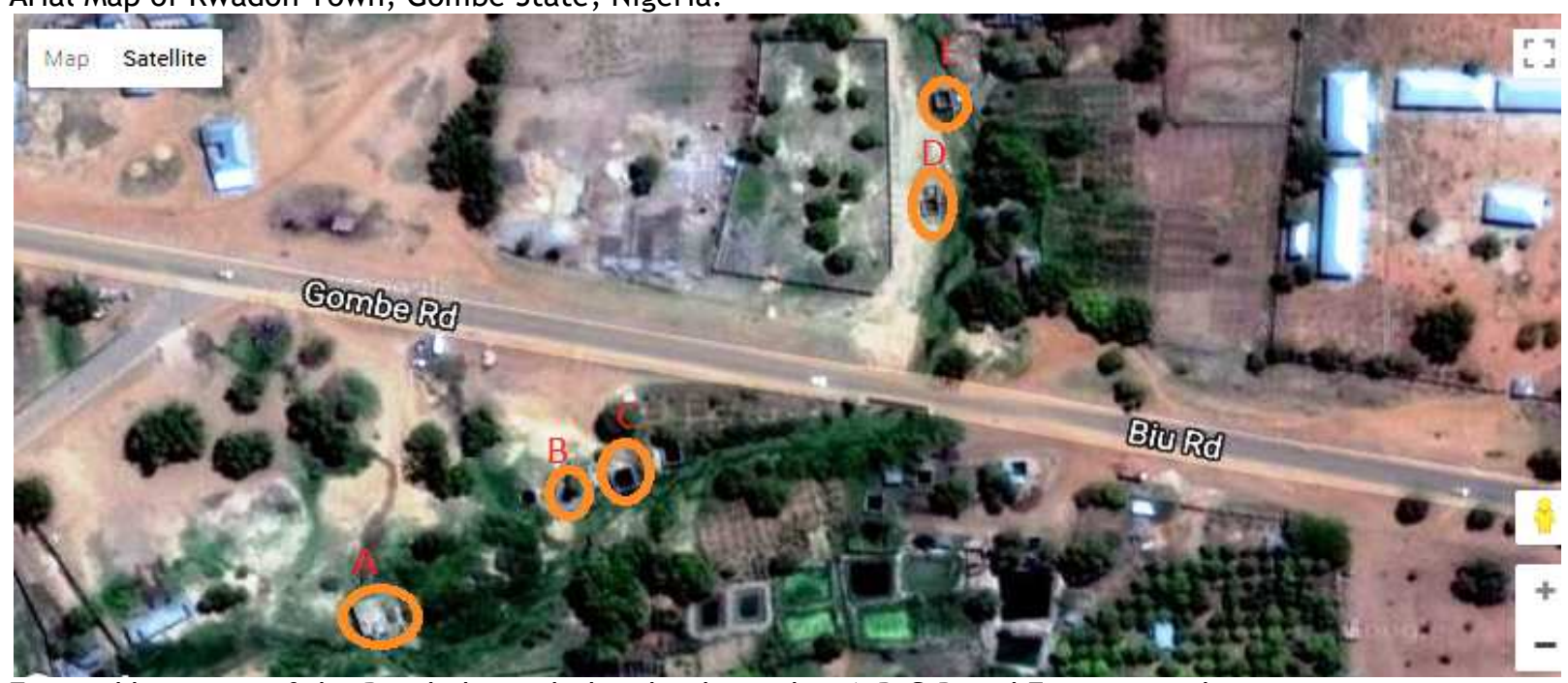

Zoomed locations of the Borehole circled and indicated as A,B,C,D and E respectively.

\section{Risk Assessment}

Risk assessment can be said to be a function of hazard and exposure and is defined as the process of estimating the probability of occurrence of an event and the probable magnitude of adverse health effects on human exposures to environmental hazards over a period of time (Wongsasuluk et al., 2014 and Adamu et al., 2015). Lee et al., (2005) reported that risk assessment consists of hazard identification, exposure assessment, dose response (toxicity) and risk characterization. The health risk assessment of each potentially toxic metal is usually based on the quantification of the risk level and is expressed in terms of a carcinogenic or non-carcinogenic health risk. Two toxicity risk indices reported are the slope factor (SF) for carcinogenic risk characterization and the reference dose (RfD) for non-carcinogenic risk characterization (Adamu et al., 2015).
The health risk from the borehole water consumption was assessed according to its noncarcinogenic effects based on the following equation which is a similar representation of daily exposure route modified from USEPA (1992) and Chrostowski (1994) and adopted by Kavcaret al.,(2009):

$$
C D I=C \times \frac{D I}{B W}
$$

Where $C D I$ is the chronic daily intake $(\mathrm{mg} / \mathrm{kg} / \mathrm{d}), \mathrm{C}$ is the drinking water contaminant concentration $(\mathrm{mg} / \mathrm{l})$, $\mathrm{DI}$ is the average daily intake rate of drinking water $(\mathrm{l} / \mathrm{d})$, and $\mathrm{BW}$ is the body weight in $(\mathrm{kg})$.

The Hazard Quotient, (HQ) is calculated using the following equation (USEPA, 1999, and Kavcar et al, 2009): $\mathrm{HQ}=\mathrm{CDI} / \mathrm{RfD}$

Where RfD is the reference dose $(\mathrm{mg} / \mathrm{kg} / \mathrm{d}) \cdot \mathrm{RfD}$ values employed in this study were obtained from the USEPA (IRIS, 2010). 
Special Conference Edition November, 2017

Health Risk assessment of the toxicants was interpreted based on the values of $\mathrm{HQ}$ and THI. Values less than $(\mathrm{HQ}$ or $\mathrm{THI}<1)$ means an acceptable level of non-carcinogenic risk and the greater the values above one, the greater is the non-carcinogenic risk level of the toxicants manifesting long term health hazard effects increasing (Wang, 2012;Adamuet al., 2015).

Total Hazardous Index (THI)

To estimate the risk to human health through more than one heavy metal, the hazard index (HI) has been developed (USEPA, 1989). The hazard index is the sum of the hazard quotients for all heavy metals, which was calculated by the eqn. ( Limet al., 2008; Guerra et al., 2010). $T H I=\sum H Q_{i}$

It assumes that the magnitude of the adverse effect will be proportional to the sum of multiple metal exposures. It also assumes similar working mechanisms that linearly affect the target organ.

\section{RESULTS AND DISCUSSION}

Concentrations of the metals determined in this study are as presented in Table 1 . The Chronic Daily Intake and Hazard Quotient are also presented in the same table. The HQ for iron calculated for adults and children respectively is $0.516 \mathrm{mg} / \mathrm{kg} / \mathrm{day}$ and $0.635 \mathrm{mg} / \mathrm{kg} / \mathrm{day}$ respectively. All these values fall below the recommended daily dose of iron, thus making iron a non-hazardous metal in water from Kwadon boreholes. The $\mathrm{HQ}$ value for iron in water from Kwadon boreholes fall below one, thus making iron safe to those exposed to the water in Kwadon boreholes. Manganese had a CDI value of $0.051 \mathrm{mg} / \mathrm{kg} /$ day and 0.069 $\mathrm{mg} / \mathrm{kg} /$ day for adults and children respectively. These values in this study are all above the $R_{f} D$ value of manganese in water, thus manganese poses a potential health risk in water from Kwadon boreholes as the $\mathrm{HQ}$ are all above one both for adults and children. Table 1 also shows the HQ of copper in water from Kwadon boreholes. All the values are above unity for both adults and children thus making copper a potential health risk to those exposed to the water in Kwadon boreholes.

The HQ of cadmium in water from Kwadon boreholes for both adults and children is as depicted in Table 1. These are all below one. All these values fall below the daily recommended dose of cadmium in water, thereby making cadmium safe in the drinking water of Kwadon boreholes. Nickel poses no health risk to those exposed to the water from Kwadon boreholes as Table 1 gives the $\mathrm{HQ}$ values for nickel in Kwadon boreholes as 0.18 for adults and 0.24 for children respectively.

The same Table 1 gives the $\mathrm{HQ}$ for cobalt in water from Kwadon boreholes which are all above unity for adults and children as3.67 $\mathrm{mg} / \mathrm{kg} / \mathrm{l}$ and $4.33 \mathrm{mg} / \mathrm{kg} / \mathrm{l}$ for adults and children respectively. Therefore, cobalt poses a potential health threat to those exposed to the water from Kwadon boreholes as the noncarcinogenic risk is high.

The CDI values of zinc from this study from the water in Kwadon boreholes are 0.052 $\mathrm{mg} / \mathrm{kg} /$ day for adults and $0.070 \mathrm{mg} / \mathrm{kg} /$ day for children. This values fall below the $R_{f} D$ of zinc in water which is $0.3 \mathrm{mg} /$ day, thereby making zinc safe in the water from Kwadon boreholes. Table 1show the HQ of zinc in water from Kwadon boreholes which are all below unity, thus confirming the safety of zinc.

The THI values for both adults and children were all greater than unity. The contributing metals to this high THI value are manganese, copper and cobalt. Thus, there is a need for further monitoring of these metals in water from Kwadon boreholes especially for children as they have a greater tendency of accumulating these metals over a longer period of time.

Table 1: Levels of metals, Chronic Daily Intake (mg/kg/day), Hazard Quotient and THI of waterfor adults and children in water from Kwadon Boreholes

\begin{tabular}{llllll}
\hline & $\begin{array}{l}\text { CDI } \\
(\mathrm{mg} / \mathrm{kg} / \text { day })\end{array}$ & & HQ & & $\begin{array}{l}\text { metal conc. } \\
\mathrm{mg} / \mathrm{l}\end{array}$ \\
\hline Metal & Adult & children & Adult & children & \\
\hline $\mathrm{Fe}$ & 0.065 & 0.088 & 0.516 & 0.635 & 1.32 \\
$\mathrm{Mn}$ & 0.051 & 0.069 & 1.109 & 1.500 & 1.03 \\
$\mathrm{Cu}$ & 0.074 & 0.01 & 7.400 & 10.00 & 0.15 \\
$\mathrm{~Pb}$ & $\mathrm{ND}$ & $\mathrm{ND}$ & $\mathrm{ND}$ & $\mathrm{ND}$ & 0.00 \\
$\mathrm{Cd}$ & 0.018 & 0.024 & 0.18 & 0.24 & 0.36 \\
$\mathrm{Ni}$ & 0.004 & 0.005 & 0.18 & 0.24 & 0.07 \\
$\mathrm{Co}$ & 0.001 & 0.001 & 3.67 & 4.33 & 0.02 \\
$\mathrm{Zn}$ & 0.052 & 0.070 & 0.173 & 0.23 & 1.06 \\
$\mathrm{THI}$ & & & 13.225 & 17.18 & \\
\hline
\end{tabular}




\section{CONCLUSION}

The levels of some metals were determined by AAS and then used to determine the health risk potentials of these metals via drinking water. Manganese, copper and cobalt were determined to have potential non-carcinogenic risk potentials for both adults and children. The risk was higher for children than adults as the

\section{REFERENCES}

Adamu, C.I; Nganje, T.N. and Edet, A. (2015). Heavy Metal Contamination and health Risk assessment associated with abandoned barite mines in Cross River State, South Eastern Nigeria. Environmental Nanotechnology, Monitoring and Management 3 pp10-21

Chrowtoski, P. C., (1994). Exposure assessment principles. In: Patrick, D. R. (ED), ToxicAir Pollution Handbook. Van Nostrand Reinhold, New York, NY, pp154.

Enaam JA (2013). Evaluation of Surface Water Quality Indices for Heavy Metals of DiyalaRiver Iraq. J. Nat. Sci. Res. 3(8):63-64.

Guerra, K., Konz, J., Lisi, K. And Neebrem, C. (2010). Exposure Factors Handbook.USEPA, Washington DC.

Hinrichsen D, Tacio H (2002). The coming fresh water crisis is already here. Finding the source: The linkages between population and water. Woodrow Wilson International Center for Scholars, Washington, DC, ESCP Publication spring.

IRIS (Integrated Risk Information System) (2010).US Environmental Protection Agency, Cincinnati, OH. Accessed at: <http://www.epa.gov/iris>

Kavcar, P., Sofuoglu, A., and Sofuoglu, S. C. (2009).A health risk assessment for exposure to trace metals via drinking water ingestion pathway.International Journal of Hygiene and Environmental Health, 212:216-227.

Koki, I.B.; Bayero, S. A.; Umar, A and Yusuf, S.(2015). Health Risk Assessment of Heavy Metals in water, air, soil and Fish : A Review.African Journal of Pure and Applied Chemistry 9(11) pp204210.

Lee, j. S.,Chon, H. T. and Kim, K. W. (2005). Human health risk assessment of As, $\mathrm{Cd}, \mathrm{Cu}$ and $\mathrm{Znin}$ the abandoned metal mine site. Environ. Geochem. Health 27 pp185-191. hazard quotient for these metals in children was found to be higher than for adults. There is a potential health risk from a cumulative accumulation of consuming the water from Kwadon boreholes over a period of time as shown by the total hazard index which was higher than one with major contributions from manganese, copper and cobalt.

Li S, Liu W, Gu S, Cheng X, Xu Z, Zhang Q (2009). Spatio-temporal dynamics of nutrients in the upper Han River basin, China. J. Hazard. Mater. 162(2):1340.

Lim,H. S.,Lee, J. S., Chon,H. T. and Sager, M. (2008). Heavy metal contamination and health risk assessment in the vicinity of the abandoned Songcheon $\mathrm{Au}-\mathrm{Ag}$ mine in Korea. J. Geochem. Explor. 96 pp223-230

Maigari, A. U.; Ekanem, E. O.; Garba, I. H.; Harami, A. and Akan, J. C. (2016). Health Risk Assessment for Exposure to some selected Heavy Metals via Drinking water from Dadin kowa Dam and River Gombe Abba in Gombe State, Northeast Nigeria. World

Journal of Analytical Chemistry 4(1) pp1-5

Nwachukwu, E. R., Ihedioha, J. F., Eze, I. S. and Agbazue, V. E. (2014). Health risk assessment in relation to heavy metals in water sources in rural regions of South East Nigeria.International Journal of Physical Sciences, 9(6):109116.

USEPA (1992).Guidelines for Exposure Assessment.EPA/600/Z-92/001.US Environmental Protection Agency, Risk Assessment Forum, Washington, DC.

U.S.EPA,(1999): Drinking water and Health.EPA816-k-99-001.

USGAO, (2000): Health Effect of lead in drinking water. U.S. General Accounting Officereports 2000.

Wang XL, Sato T, Xing BS, Tao S (2005). Health risks of heavy metals to the general public in Tianjin, China via consumption of vegetables and fish. Sci. Total Environ. 350:28-37

Wongasasuluk, P., Chotpantatarat, S.mSiriwong, W. and Robson M. (2014). Heavy metal contamination and human health risk assessment in drinking water from shallow groundwater wells in an agricultural area in UbonRatchathani province, Thailand. Environ. Geochem. Healt 36 pp169-182. 